\title{
Het taal- en spraakgestoorde kind
}

Citation for published version (APA):

Marres, E. H. M. A. (1982). Het taal- en spraakgestoorde kind. Rijksuniversiteit Limburg. https://doi.org/10.26481/spe.19820122em

Document status and date:

Published: 22/01/1982

DOI:

10.26481/spe.19820122em

Document Version:

Publisher's PDF, also known as Version of record

\section{Please check the document version of this publication:}

- A submitted manuscript is the version of the article upon submission and before peer-review. There can be important differences between the submitted version and the official published version of record.

People interested in the research are advised to contact the author for the final version of the publication, or visit the DOI to the publisher's website.

- The final author version and the galley proof are versions of the publication after peer review.

- The final published version features the final layout of the paper including the volume, issue and page numbers.

Link to publication

\footnotetext{
General rights rights.

- You may freely distribute the URL identifying the publication in the public portal. please follow below link for the End User Agreement:

www.umlib.nl/taverne-license

Take down policy

If you believe that this document breaches copyright please contact us at:

repository@maastrichtuniversity.nl

providing details and we will investigate your claim.
}

Copyright and moral rights for the publications made accessible in the public portal are retained by the authors and/or other copyright owners and it is a condition of accessing publications that users recognise and abide by the legal requirements associated with these

- Users may download and print one copy of any publication from the public portal for the purpose of private study or research.

- You may not further distribute the material or use it for any profit-making activity or commercial gain

If the publication is distributed under the terms of Article $25 \mathrm{fa}$ of the Dutch Copyright Act, indicated by the "Taverne" license above, 
Het taal-en spraakgestoorde kind 



\section{Het taal-en spraakgestoorde kind}

\section{REDE}

uitgesproken bij de aanvaarding van het ambt van Hoogleraar in de Keel-Neus-Oorheelkunde aan de Rijksuniversite it "Limburg"

te Maastrich op vrijdag 22 januari 1982 door DrE.H.M.A. Marres 
Gedrukt bij Schrijen-LippertzBV

Vocrendaal. 
Dames en Heren Leden wan het Universiteisbesturu,

Dames en Heren Leden wan de Universiteitsraad, Dames en Heren Hoogleraren, Docenten en Leden van de Wevenschappelijke Staf,

Dames en Heren Siudenten en vooris Gijallen. die door Uw an wezigheid blikt geeft van Uw belangstelling,

\section{Zeer gewaardeerde toehoorders,}

Steeds vaker komt het voor, dat ouders samen met hun kind het spreekuur van de keel- neusen oorarts bezoeken, omdat hun kind een stoornis wertoont in het spreken. Deze stoornis kan zich manifesteren doordat hun kind op een onjuiste wijze de woorden, die hij zegt, uitspreekt doch ook bestaat de mogelijkheid, dat hun kind onvoldoende of zelfs helemaal miet in stat is met de omgeving verbaal te communiceren.

In het eerste geval hebben wij waarschijnlijk te maken met een kind, dat een voldoende kennis van de taal bezit doch een gestoorde uitspraak heeft en in het tweede geval is er waarschijnlijk sprake, dat wij een kind on tmoet hebben, dat een stoornis heeft in de taalverwerving. Uit het gesprek met de ouders blijkt al heel spoedig, dat zij zeer bezorgd zijn over de problematiek, die zij bij hun kind hebben aangetroffen.

Dit is mijns inziens terecht, omdat immers de taal en de spraak van bijzonder groot belang zijn woor de onderlinge relatic tussen de mensen. Het is het belangrijkste middel om met elkaar in contact te komen en met elkaar om te gaan. Daamaasi 
is het bezit van taal van grote importantie voor de ontwikkeling van het denken. Wij denken met behulp van de taall en de kennis hiervan is eveneens een belangrijk hulpmiddel bij het overbrengen van onze gevoelens en gedachten.

De sociale contacten zijn hiervan afhankelijk en zo ook de opvoeding van onze kinderen en de overdracht van onze kennis.

Taal- en spraakgestoorde kinderen dienen daarom vroeg opgespoord en behandeld te worden.

Binnen de taal kunnen wij vier regelsystemen onderscheiden en deze regels zijn op alle spreektalen van toepassing. Deze zijn de volgende:

\section{De Fonologie}

Deze geeft het systeem van klanken aan, welke in een bepaalde taal woorkomen. Iedere taal heeft dienaangaande zijn eigen kenmerken. In de nederlandse taal komen bijvoorbeeld geen klanken voor, die men uitspreekt met de tong tussen de tanden, doch dit is in de engelse taal wel het geval. Ik denk daarbij aan de klank "th".

\section{De Semantiek}

Deze houdt zich bezig met de betekenis van de woorden en de gebruikte woordenschat van de diverse talen en dialecten.

\section{De Syntaxis}

Onder de syntaxis verstaat men de woordvolgorde en zinsconstructie, die bij de talen van toepassing zijn. 
Deleer van de zinsbouw van de taal wordt hiermee bedoeld.

\section{De Morfologie}

Onder de morfologie van de taal wordt de vorm van de woorden bedoeld, die in een bepaalde context worden gebruikt, zoals de meervoudsvorming, verbuigingen en vervoegingen.

Teder sprekend individu dient zich tijdens het spreken van een bepaalde taal of dialect aan deze regels te houden.

Hoe verloopt nu de normale taal- en spraakontwikkeling bij het kind? De verwerving ervan dient plaats te vinden tussen de nul en vijf jaar en deze ontwikkeling is gebaseerd op het principe, dat bij het mondelinge taalgebruik het spreken, de zogenaamde expressie, in balans dient te zijn met het taalverstaan of begrijpen, hetgeen de receptie van de taal wordt genoemd. Het verstaan en begrijpen van de taal enerzijds en het spreken ervan anderzijds dienen zich volgens de genoemde taalregels harmonieus te ontwikkelen, indien men mondeling met elkaar op een goede wijze wil communiceren.

Bij de normale taalverwerving tussen de nul en vijf jaar kan men in grote lijnen drie belangrijke perioden onderscheiden. 


\section{De prelinguale periode (0-1 jaar)}

Deze periode ligt tussen de leafijd van nul en én jaar. Na de geboorte maakt het kind hulend zijn eerste gelluid. Bij een goedhorend kind zal na de geboorte al snel het luisteren naar auditieve stimuli tot ontwikkeling komen. Het kind leert, dat deze stimuli kunnen varièren in toonhoogte. in intensiteit en tijdsduur. Ook het richting horen komt tot ontwikkeling en zo ook leren wij verschillende geluiden van elkaar onderscheiden. Het leren luisteren van het kind kan vanzelfsprekend gestimuleerd worden door veel tegen de kinceren te praten, geluidjes te maken etc. Dit stimuleren van het leren luisteren door het kind is wan belang bij de taalverwerving. Er ontstaat op deze wijze een interactic tussen het kind en zijn omgeving. Het kind begint als het ware een cognitieve structuar op te bouwen en selectief te reageren op bepaalde stimuli vanuit zijn omgeving. Op ongeveer zes weken na de geboorte begint het kind klinkerachtige geluiden te produceren vooral ontlokt door sociale stimuli. Wij noemen dit het vocaliseren van het kind. De variatie in de geproduceerde geluiden van het kind wordt steeds groter, omdat het kind steeds meer de lippen en de tong gaat gebruiken en wij komen in de brabbelfase. In deze zogenaamde brabbelperiode, welke ongeveer vier maanden na de geboorle begint en ongeveer duurt tot het eerste levensjaar, gaat de imitatie steeds meer een belangrijke rol spelen, omdat het brabbelen zich steeds meer ontwikkelt in de richting van de moedertaal. Wij komen nu in de tweede periode van de taalverwerving: de vroeglinguale periode. 
Deze periode ligt tussen de leeftijd van eén en drie jaar.

Op deze leeftijd zijn de kinderen in staat klanken en klankpatronen van elkaar te onderscheiden. Zij gaan beseffen, dat bij bepaalde dingen bepaalde woorden horen en zij beginnen zich uit te drukken met éénwoordzinnen.

Een woordenschat wordt opgebouwd en op de leeftijd van drie jaar spreekt het kind in drie- of meerwoord zinnen, indien er een normale ontwikkeling van de taal en de spraak plaatsvindt.

\section{De differentiatie fase ( $3-5$ jaar)}

Deze periode duurt vanaf het derde tot het vijfde levensjaar. In deze periode worden de taal en de spraak van het kind verder uitgebouwd en verfijnd, zodat er bij het kind betreffende deze ontwikkeling een differentiatie optreedt in de richting van de fonologie en semantiek en tenslotte ook tussen het vijfde en zevende levensjaar een differentiatie in de syntaxis en morfologie van de taal, zich manifesterend in de spraak, welke het kind produceert. Het spreken wordt voor het kind steeds meer het effectiefste communicatiemiddel tussen hem zelf en de personen in zijn omgeving en deze gaan van hun kant steeds meer eisen stellen aan de spreekvaardigheid van het kind.

De voor U geschetste taalverwerving en taalvaardigheid bij het kind kan alleen dan harmonisch verlopen, indien aan de volgende voorwaarden wordt voldaan. 
Het kind moet een goed functionerend gehoor en een goede auditieve discriminatic hebben. Daarnaast dient het kind in het bezit te zijn van goed functionerende spreekorganen en een normaal functionerend zenuwstelsel. Ook de intellectuele capaciteiten wan het kind moeten in woldoende mate aanwezig zijn. De mogelijkheid om te kunnen en te willen spreken dient bij het kind aanwezig te zijn, hetgeen ook wel de sociale vaardigheid van het kind genoemd wordt. Daarnaast is een normale emotionele ontwikkeling van het kind voor de taalverwerving en taalvaardigheid van belang. Ook het taalaanbod vanuit het milieu is voor deze ontwikkeling van grote betekenis.

Is de taalontwikkeling en taalvaardigheid van een kind gestoord, dan wordt dit door de ouders maar ook door het kind zelf steeds pijnlijker ervaren. Beiden worden onzeker. Het kind merkt, dat hei dienaangaande niet aan de verwachtingen van de personen uit zijn omgeving voldoet en andersom is dit eveneens het geval.

Men dient zich daarbij te realiseren, dat de taalontwikkeling van het kind geen een op zich zelfstaand verschijnsel is, maar dat deze ontwikkeling ook samenhangt met de andere ontwikkelingsaspecten van het kind, zoals de verstandelijke ontwikkeling, de sociaal-emotionele ontwikkeling en de sensomotorische ontwikkeling van het kind. Een taalontwikkelingsstoornis zal dus de andere ontwikkelingsaspecten zeker nadelig beinvloeden. Zo ook kan men een taalontwikkelingsstoornis beschouwen als een niel specifieke stoornis, maar als een uiting van een stoornis in het totale ontwikkelingsproces van het kind. 
Wanneer nu dient een onderzoek van een spraakgestoord kind plats te vinden:

1. Wanneer een kind van twee jaar nog niets zegt.

2. Wanneer een kind van drie jaar nog geen woordcombinaties maakt.

3. Wanneer een kind van vier jaar nog onverstaanbaar is voor een vreemde.

Na het afnemen van de anamnese, waarbij uitvoe rig ingegaan moet worden op de formulering van het probleem, op de algemene en specifieke ontwikkelingsgegevens t.a.v. de taalontwikkeling en de interactie tussen kind en ouders, dient nagegaan te worden, hoe de verbale en niet verbale vaardigheden van het kind zijn.

Bij het onderzoek naar de niet verbale vaardigheden van het kind moeten het gehoor, de auditieve discriminatie, het visueel gericht zijn en de mentale capaciteiten van het kind worden onderzocht. Daarnaast dient een algemeen medisch onderzoek plaats te vinden, waarbij vooral gelet moet worden op de senso-motoriek en de functie van de spraakorganen. Vervolgeris moeten de emotionele en sociale gedragingen van het kind worden geobserveerd vooral in relatie met de ouders van het kind.

Betreffende het onderzoek naar de verbale vaardigheden is het van belang te weten of het kind veel gebrabbeld heeft en wanneer en zo ook wanneer en welke woordjes en zinnen het kind heeft uitgesproken. Daarnaast moet door middel van testen worden uitgezocht, hoe het woordbegrip en woordgebruik wan het kind zijn en of her kind begrip heeft van de vormveranderingen, die in de taal voorkomen. Tijdens deze testen moet men 
eveneens letten op de auditieve en visuele aandacht wan het kind en op het feit, hoe het kind reageert, wat het kind begrijpt en wat niet. Uit dit zeer tijdrovende onderzoek hoopt men de verhouding te leren kennen van de verbale en niet verbale ontwikkeling van het kind, althans het streven is hierop gericht.

Immers, zoals reeds gezegd, dient ert.a.y de taalontwikkeling een evenwicht te bestaan tussen het taalverstaan, de receptie, en de spraakvaardigheid, de expressie. Wanneer de verbale en niet verbale ontwikkeling van het kind niet in harmonie met elkaar tot ontplooing komen, ontstaat er een stoornis in de taal-e en spraakontwikkeling.

Welke stoornissen kunnen wij zoal in het taalfunctioneren vinden?

Men moet een onderscheid maken tussen een vertraagde taalontwikkeling en een stoornis in de taalontwikkeling. Laat ik enkele voorbeelden noemen om dit te verduidelijken. Bij een kind kan de taalontwikkeling vertraagd verlopen, omdat de verstandelijke mogelijkheden van het kind beperkt zijn. De taalontwikkeling bij dit type kind kan zich normaal ontwikkelen alleen verloopt deze trager, zodat er ten aanzien van de leeftijd van het kind een taal-en spraakontwikkelingsachterstand ontstaan. Deze vertraging kan ook ontstaan, indien de neuromotorische ontwikkeling van het kind niet normaal is. Doch ook andere stoornissen in de ontwikkeling van her kind kunnen een vertragende invloed hebben op de taalen spraakontwikkeling van het kind. Het zou te wer voeren hiervan een opsomming te geven. Wij 
spreken van een echte stoomis in de taalontwikkeling, indien sommige aspecten van de taalontwikkeling op een normale wijze tot stand komen, doch andere aspecten in deze een selectieve uitval vertonen. Wij treffen dan fouten en achterstanden aan op het gebied van de fonologie, de semantiek, de morfologie en syntaxis van de taal. Is er bijvorbeeld een stoornis in de fonologie dan vervormt het kind de klinkers en medeklinkers. Maakt het kind fouten in de zinsconstructie dan zondigt hij tegen de syntaxis van de taal.

Uit hetgeen tot nu toe door mij maar voren gebracht is blijkt overduidelijk, dat een normale taal- en spraakontwikkeling de resultante is van een zeer complex gebeuren in de eerste levensjaren van het kind. Eveneens blijkt overduidelijk, dat er vele oorzaken kunnen zijn, waardoor de taal- en spraakontwikkeling kan derangeren. Is dit laatste het geval, dan komt het probleem aan de orde hoe deze moeilijkheid voor het kind en de ouders het beste kan worden opgelost. Hiervoor bestaan helaas op dit moment nog veel onzekerheden, omdat er bij de onderkenning en hulpverlening aan kinderen met spraaktaalstoornissen nog geen vanzelfsprekende en pasklare oplossingen voorhanden zijn.

Allereerst zal het $u$ duidelijk zijn, dat een vroege opsporing van kinderen met taal- en spraakproblemen van groot belang is voor het kind en de ouders. Uit onderzoeken blijkt, dat er bij vijf procent van alle kinderen taal-en spraakstoornissen worden aangetroffen. Een vroege opsporing van deze kinderen is noodzakelijk om bij de eerste tekenen van het ontstaan van taal en spraakproblemen 
in te kunnen grijpen en de oorzaak van dit ontstaan op te sporen om daardoor adequaat hulp te kunnen bieden. De moeilijkheid bij deze opsporing is, dat er op dit moment nog geen goede screeningsmethoden zijn om deze stoornis te onderkennen. Om een vroege opsporing van deze kinderen te bevorderen is het mijns inziens zeker van belang, dat de artsen, verbonden aan de consultatiebureaux voor jonge kinderen, duidelijke vragen moeten stellen aan de ouders over de taalen spraakontwikkeling van de kinderen, die zij onderzoeken. $\mathrm{Zij}$ dienen daarom op de hoogte te zijn van de normale taal-en spraakontwikkeling van het kind en de stoornissen, die op dit gebied kunnen ontstaan. Het is op dit moment een goede zaak, dat ten aanzien van het opsporen van kinderen met een slechthorendheid de Ewing-test vrijwel op alle consultatiebureaux wordt toegepast. Zo ook zou het goed zijn, dat er screeningsmethoden worden ontwikkeld, waarmee de taal- en spraakontwik keling van een kind kan worden vastgesteld. Op dit moment zijn er wel testmethoden voorhanden, die daarvoor geschikt zijn, doch het kost nog teveel tijd om deze testen als routine bij ieder kind af te nemen. De vraag is echter of het niet alleszins de moeite waard zou zijn om bij een aantal consultaticbureaux een zo gericht mogelijk onderzock te doen naar de taal- en spraakontwikkeling van de kinderen, die worden onderzocht, om screeningsmethoden tot ontwikkeling te brengen. 
Wordt bij een kind via een Ewing-test een slechthorendheid vermoed dan wordt dat kind nu naar de huisarts of naar een keel-neus- en oorarts verwezen of indien nodig natar een audiologisch centrum. Moeilijker is echter de vraag hoe te handelen, wanneer een kind spraakgestoord blijkt te zijn. Wie komen dan voor een nader onderzoek van deze kinderen in aanmerking? Op dit moment kunnen dat de huisarts, de kinderarts, de keelneus-en oorarts, de neuroloog, de psycholoog, de pedagoog en de logopedist zijn en daarnaast bestaan er nog diverse centra bij wie deze kinderen terecht kunnen komen, zoals de audiologischeen logopedische centra, medisch opvoedkundige bureaux etc. Gezien deze veelheid van mogelijkheden van verwijzing van deze kinderen voor nader onderzoek gebeurt het nog al te vaak, dat er een foutieve verwijzing plaatsvindt, waardoor er een vertraging ontstat in de behandeling van het kind. Ik geloof, dat het daarom goed is een waarschuwend woord te laten horen betreffende de opvang van deze kinderen, daar het te vaak voorkomt, dat er een onvoldoende samenwerking bestaat tussen de diverse disciplines, die het lot van deze gehandicapte kinderen aantrek ken.

Naar mijn mening beoordelen bijvoorbeeld de medici deze kinderen vaak te medisch of te somatisch zo men wil, en de niet medici doen dit, overigens met alle goede bedoelingen van dien, vaak te pedagogisch. Benadrukken wil ik daarom, dat het het kind is, dat in het middelpunt van de belangstelling dient te staan en niet het beroep, waarmee het kind in aanraking is gekomen. Laat ik een voorbeeld noemen. Het komt nog te vaak voor, dat een spraakgestoord kind te lang behan- 
deld wordt door een logopedist, terwijl het kind licht slechihorend of motorisch gestoord is. Zo ook gebeurt het te vaak dat een slechthorend kind te lang behandeld wordt door een keel-neusm en oorarts zonder te letien op de psychosociale ontwikkeling van het kind. I zou daarom willen pleiten voor een zeer intensieve en nauwkeurige samenwerking tussen de diverse disciplines, die deze spraakgestoorde kinderen onder hun hoede hebben. Zij moeten elkaar vaker en vooral sneller consulteren m.a.w. het belang van ieders kumen beter leren inzien. ledere maand delay in een adequate behandeling van het kind betekent voor het kind een vertraging in zijn ontwikkeling en een toename van de bezorgdheid, die de ouders om deze kinderen hebben.

Om deze vertraging in de behandeling van deze kinderen te ondervangen zou ik willen pleiten voor het oprichten van "Speech - and Hearing centers" naar amerikaans model. De bestaande audiologische centra, die gewend zijn kinderen met gehoorstoornissen en dientengevolge ook vaak met spraakstoornissen te onderzoeken, dienen te worden gecombineerd met de bestaande logopedische centra of te worden uitgebreid met logopedische centra om sneller een therapeutisch advies aan deze probleem-kinderen te kunnen geven.

Aan deze gecombineerde audiologische- en logopedische centra dienen de genoemde disciplines verbonden te zijn om ieder hun eigen bijdrage aan de behandeling van het kind te leveren. De medewerkers wan deze centra moeten vamzelfsprekend optimaal samenwerken met de huisartsen van deze kinderen. Ook in organisatorisch opzicht 
zal dit een voordeel zijn, daar dan efficiẻnt geprofiteerd kan worden van elkars know-how en een delay in de diagnostiek en de behandeling van het kind kan op deze wijze tot een minimum beperkt worden.

Aan het einde gekomen van deze eerste inaugurale rede aan deze universiteit zij het mij vergund gebruik te maken van de goede gewoonte enkele dankwoorden uit te spreken.

Mijne Dames en Heren leden van het Universiteitsbesturar en van de Universiteitsraad van de Rijksuniversiteit "Limburg",

U zult begrijpen, dat ik U dankbaar ben, dat $U$ meegewerkt hebt aan mijn benoeming tot hoogleraar in de keel-neus-oorheelkunde door Hare Majesteit de Koningin. Ik zeg $U$ toe mij volledig in te zetten voor de vervulling van mijn taak aan deze jonge universiteit .

Dames en Meren leden van de faculteit der Geneeskunde van de Rijksuniversiteit "Limburg",

Veel dank ben ik $U$ verschuldigd voor de goede samenwerking en het vertrouwen, dat ik van $U$ in het afgelopen jaar mocht ontvangen. Uw hartelijk welkom in deze faculteit heb ik zeer op prijs gesteld. Ik heb daarom het vertrouwen gekregen, dat de onderlinge contacten in de toekomst alleen maar op een goede manier kunnen worden verstevigd. 
Dames en Heren leden van het Besturu, van de Directie en Collegae van het ziekenhuis" "St. Annadal" en van het ziekenhus "Maastricht",

Het is ntet nodig voor $U$ verborgen te houden, dat het voor mij niet gemakkelijk was op 1 januari 1981 in Uw ziekenhuis aan het werk te gaan na zoveel jaren in volle tevredenheid elders gewerkt te hebben. Uw zuidelijke gastwrijheid doch vooral ook Uw medewerking tijdens de start in Uw ziekenhuis hebben mij hoopvol gestemd voor de toekomst. Ik dank U hiervoor zeer hartelijk. Mijnerzijds kunt $U$ erop rekenen, dat ik mij volledig in zal zetten om samen met $U$ en met mijn directe medewerkers de afdeling keel-neus-oorheelkunde uit te bouwen in Uw ziekenhuis en in het toekomstig academisch ziekenhuis.

Dames en Heren leden van het Bestuur van de Universileit en van de Faculteil der Geneeskunde te Nijmegen. Dames en Heren leden van het Bestuur, wan de Directie en van het Stafconvent van het "St. Radboudziekenhuis" te Nijmegen,

Gaarne wil ik U bijzonder hartelijk danken voor de vele bewijzen van prettige samenwerking, welke ik van $U$ in de afgelopen jaren mocht ontvangen. $1 k$ kan $U$ verzekeren, dat ik aan de jaren, verbonden aan Uw universiteit en Uw ziekenhuis, de beste herimneringen heb overgehouden. 
Dames en Heren leden van het Bestuar, wan de Directie, Collegae en medewerkers van hel Ziekenhuis te Boxmeer,

Vele jaren ben ik ook als medewerker aan $U_{w}$ ziekenhuis verbonden geweest en dit was steeds tot mijn genoegen het geval.

Het afscheid van Uw ziekenhuis viel mij daarom zwaar. De prettige onderlinge samenwerking heb ik steeds zeer gewaardeerd.

Ik ben $\mathrm{U}$ dankbaar, dat ik de kans gekregen heb in $\mathbb{U}$ w zieken huis te mogen werken.

Hooggeachte Brinkman, Beste Wim,

$U$ weet, dat ik er trots op ben in Uw kliniek tot keel-neus-en oorarts te zijn opgeleid. In de afgelopen jaren stelde $U$ veel vertrouwen in mij en ik ben $U$ daar zeer erkentelijk voor. De kunst, die $U$ verstaat cen harmonicuse samenwerking te creëren tussen UW medewerkers is voor mij altijd een voorbeeld geweest. $I k$ ben $U$ meer dan ik zeggen kan dankbaar voor alles wal $\mathrm{U}$ voor mij deed. Ik wens Uw opvolger Paull van den Broek succes toe in zijn nieuwe taak.

Dames en Heren medewerkers van de Staf en van de afdeling keel-neus-en oorheelkunde van het "St. Radboudziekenhuis" te Nijmegen.

Tijdens de jaren, die ik te midden van $U$ mocht werken, heb ik veel vriendschap van $U$ ontwangen. Hiervoor ben ik U zeer dankbaar. Gaarne spreek ik mijn waardering uit voor de nauwkeurigheid, 
de plichtsbetrachting en deskundigheid, waarmee $U$ de keel-neus- en oorheelkunde beoefent. Deze eigenschappen zullen voor mij een voorbeeld blijven bij het uitoefenen van mijn taak te Mastricht.

Mijne Heren leden wan de Staf van de afdeling keel-neus-en oorheelkunde re Maastricht.

Gaarne laat ik U vanaf deze plaats weten, dat ik dankbaar ben woor de hartelijke en collegiale wijze, waarop $U$ mij in $U w$ midden hebt opgenomen. Onze taak om samen in de toekomst een goed functionerende keel-neus-oorheelkundige afdeling op academisch niveau op te bouwen is niet gemakkelijk. Ik dacht, dat wij het afgelopen jaar samen een goede start hebben gemaki en ik zie dan ook de toekomst met optimisme tegemoet.

Dames en Heren medewerkers en verpleegkundigen varn de afdeling keel-neus- en oorheelkunde van het ziekenhuis" Maastricht",

Uw werk, Uw ijver en vooral ook Uw toewijding en zorg voor de zieke medemens zijn van onschatbare waarde. Het afgelopen jaar is mij gebleken, dat $U$ zich hiervoor inzet. Dit is gezien de grote vooruitgang in ons specialisme voorwaar geen lichte taak. Mijnerzijds zeg ik $U$ mijn steun in deze volledig toe. 
Dames en Heren medewerkers van he logopedischen audiologisch centrum te Hoensbroek,

Uw spontaan aanvaarden om een goede samenwerking op te bouwen tussen Uw centra en de afdeling keel-neus- en oorheelkunde van het ziekenhuis te Maastricht stemt mij jegens $U$ dankbaar. Ik ben Uw directie eveneens zeer erkentelijk deze medewerking te stimuleren. De goede samenwerking tussen Uw centra heeft mij gestimuleerd het kind, dat door $U$ wordt behandeld, hedenmiddag in het middelpunt van de belangstelling te plaatsen.

Daaruit begrijpt U tevens, dat het voor mij veel betekent mij tot Uw medewerkers te mogen rekenen.

Dames en Heren Collegae keel-neus- en oorartsen wit de omliggende ziekenhuizen en huisartsen wit de regio Maastricht,

De goede contacten. die hel laatste jaar tussen ons zijn ontstaan, stel ik zeer op prijs. Ik dank $U$ voor hel vertrouwen, dat $U$ daardoor in onze afdeling toont. Vanzelfsprekend hoop ik van harte, dat dit vertrouwen in de toekomst zal toenemen. Van mijn kant zal ik mij hiervoor volledig inzetten.

\section{Dames en Heren Studenten,}

In Uw toekomstige huisartsen-praktijk heeft een groot percentage van Uw patienten klachten op het gebied wan de keel-neus- en oorheelkunde. 
Mij bewust zijnde van het belang hiervan zeg ik $U$ toe, dat ik me zeer zal inspannen $U$ onderwijs te geven in de keel-neus- en oorheelkunde. Het onderwijs volgens het Maastrichtse model houdt mijns inziens het gevaar in zich, dat $\mathrm{U}$ te weinig in contact komt met de docenten van de diverse capaciteitsgroepen. Ik zou U daarom willen stimuleren deze contacten zoveel mogelijk te zoeken. Van mijn kant stel ik deze contacten met $U$ zeer op prijs, daar ik $U$ alleen daardoor helpen kan een voor U practische keuze te maken uit de veelheid van de aan $U$ aangeboden kennis en literatuur.

Tenslotte, en $U$ zult dit begrijpen, wil ik mijn vieugde en wooral ook mijn dankbaarheid naar woren brengen woor het feit, dat ik deze rede heb mogen uitspreken in de aanwezigheid van mijn moeder, mijn wrouw en kinderen, die allen op hun eigen wijze een grote steun voor mij zijn. 
Symposium verslag.

Nederlands instituut van psychologen, 1980 .

Swets en Zeitlinger B. V. Lisse.

Waar, C.H. e..a.,

Stem-sprakk-en taalstoomissen bij kinderen, 1980.

Siafleu's Wetenschappelijke uitgeversmatschappij B.V., Alphen aan de RijmBrussel.

Nederlandse federatic van vertegenwoordigers van ouders wan slechthorende-en sprakgestoorde kinderen, (Foss)

Kinderen met hoor-en sprakkmoeilijkheden, 1980.

Bulekers, R., Janssen, R.

Logopedie woor het onderwijs, 1979.

Uitgave Lucasstichting woor Revalidatie Hoensbroek.

Marres, E.H.M.A.,

Openbare les, 1970.

Dekker van de Vegt, Nijmegen. 